\title{
Perspectivas de desarrollo rural en la sierra de Alcaraz (Albacete) y necesidad de acciones integradas *
}

\author{
José SÁnChez SÁNChEZ * *
}

\section{INTRODUCCION}

La ruptura del sistema rural tradicional y el éxodo masivo han provocado en los municipios de estas sierras albaceteñas una situación demográfica y económica lamentable y crítica: por un lado, se enfrentan a la desvalorización de sus reducidos recursos agrícolas y forestales, deficientemente explotados por una mano de obra envejecida y escasa; por otro, tienen que afrontar la grave paradoja que representa esta mano de obra encarecida por escasa, pero que, a la vez, necesita recurrir a la emigración temporal para sobrevivir.

Análisis pormenorizados en uno de estos muncipios (Bogarra) han puesto de manifiesto una compleja coincidencia de situaciones que, como resultado actual de procesos diferentes, pueden derivar en los próximos años hacia direcciones distintas, según la manera con que se actúe sobre ciertos resortes dinamizadores que se detectan.

Las perspectivas reales de desarrollo han de apoyarse en dos tipos de factores: unos internos, o sea, los propios recursos demográficos y económicos; otros externos, esto es, actuaciones de ayuda emprendidas desde el

* Este trabajo constituyó una comunicación presentada en el I Congreso sobre Agricultura y Desarrollo Rural en Zonas de Montaña. Granada, noviembre, 1985.

** Profesor Titular de Análisis Geográfico Regional. UNED. 
exterior (tierras bajas, ciudades, centros de poder) por motivaciones de orden económico, cultural, ecológico o social.

Los factores internos existen, aunque la actual degradación de los recursos humanos y económicos, junto a los fuertes lazos de dependencia respecto a otros centros económicos, hacen imprevisible una reactivación desde dentro.

Los factores externos son los que hay que propiciar, estimular o incluso exigir. El momento es crítico porque en el proceso avanzado de empobrecimiento todavía no se ha llegado - aunque falta muy poco- al grado de lo irreversible. Pero también es un momento oportuno, ya que un nuevo concepto cultural y ecológico de los territorios montañosos ha revalorizado a estos espacios en Europa y les ha dado un lugar digno en las políticas de desarrollo rural en los paises comunitarios.

En este caso me refiero a los municipios de Ayna, Bogarra, Paterna del Madera y Riópar, situados sobre las cuencas del río Mundo y su afluente el Madera (alto Segura), en las sierras del suroeste de Albacete (fig. 1). Basándome en el análisis de la estructura demográfica y económica, valoro los escasos recursos disponibles, me apoyo en elementos que considero dinamizadores y propongo las bases de un plan integral que pretenda actuar y revalorizar este sector montañoso.

\section{RECURSOS DEMOGRAFICOS FUERTEMENTE DISMINUIDOS $Y$ FACTORES COYUNTURALES FAVORABLES}

Todos los numerosos y pequeños núcleos de estos valles han registrado pérdidas notables de población. Una vez iniciada la crisis del sistema rural tradicional se desencadenó una corriente emigratoria que en veinte o treinta años se llevó a lo más valioso de sus recursos humanos. Muchas aldeas y caseríos han quedado abandonados y en los núcleos que siguen habitados un triple proceso se puede observar: despoblación, envejecimiento e involución demográfica.

El despoblamiento queda patente en las pérdidas absolutas de habitantes, asi como en las densidades municipales. La emigración definitiva ha sido fuerte; mucho más en las entidades menores y en las más aisladas. 


\section{CUADRO ।. EVOLUCION DE LA POBLACION DE HECHO Y DENSIDADES}

\begin{tabular}{|c|c|c|c|c|c|c|}
\hline \multirow{3}{*}{ MUNICIPIOS } & \multicolumn{5}{|c|}{ VARIACION 1960-81 } & \multirow{2}{*}{ Habs. $/ \mathrm{km}^{2}$} \\
\hline & \multirow[b]{2}{*}{$\begin{array}{c}\mathrm{N} .{ }^{\circ} \text { de } \\
\text { entidades }\end{array}$} & \multicolumn{2}{|c|}{ Pob. munic. } & \multicolumn{2}{|c|}{$\begin{array}{l}\text { Pobl. en nucl. } \\
\text { princ. }\end{array}$} & \\
\hline & & Habit. & $\%$ & Habit. & $\%$ & 190019501980 \\
\hline AYNA $\ldots \ldots \ldots \ldots \ldots$ & - & -1.161 & $-3,2$ & -548 & $-32,9$ & $\begin{array}{lll}11,4 & 24,1 & 12,8\end{array}$ \\
\hline BOGARRA $\ldots \ldots \ldots \ldots$ & -3 & -1.588 & $-47,0$ & -791 & $-39,1$ & $11,2 \quad 21,5 \quad 10,8$ \\
\hline PATERNA DEL MAD. & -6 & -841 & $-54,1$ & -278 & $-37,5$ & $15,316,0$ \\
\hline RIÓPAR $\ldots \ldots \ldots \ldots \ldots$ & -1 & -907 & $-39,8$ & -149 & $-14,5$ & $33,9 \quad 34,3 \quad 14,5$ \\
\hline & -10 & -4.497 & $-43,8$ & -1.766 & $-32,4$ & \\
\hline
\end{tabular}

Fuente: Elaboración propia sobre datos del INE.

El importante volumen relativo de esta emigración ha repercutido de una forma directa y grave en la estructura de la población actual que sufre la presencia de unas clases vacías en las edades de adultos jóvenes.

El envejecimiento es muy acusado en la mitad superior de la pirámide (fig. 2) que muestra una forma claramente bulbosa, típica de sociedades envejecidas; con la diferencia de que en este caso el fuerte déficit afecta a los grupos intermedios que generan estrangulamientos sucesivos, como el que se observa en la base de la pirámide: la reducción progresiva de los grupos infantiles depende directamente de la ausencia de adultos jóvenes.

En Bogarra puede comprobarse la aceleración del proceso en los últimos 25 años, contrastando algunos datos de 1955 y 1981. 
CUADRO II. PROCESO DE ENVEJECIMIENTO (Bogarra, 1955-81)

\begin{tabular}{|c|c|c|c|c|c|c|}
\hline \multirow{2}{*}{ EDAD } & \multicolumn{2}{|c|}{1955} & \multicolumn{2}{|c|}{1981} & \multicolumn{2}{|c|}{ EVOLUCION 1955-1981 } \\
\hline & Núm. & $\%$ & Núm. & $\%$ & Número & $\begin{array}{c}\text { Indice } \\
(1955=100)\end{array}$ \\
\hline Mayores de 65 años & 269 & 7,4 & 301 & 14,7 & +32 & 112 \\
\hline Mayores de 60 años & 404 & 11,1 & 416 & 20,3 & +12 & 103 \\
\hline Mayores de 50 años & 754 & 20,7 & 754 & 36,7 & 0 & 100 \\
\hline Menores de 20 años & 1.399 & 38,4 & 639 & 31,1 & -760 & 46 \\
\hline POBLACION TOTAL & 3.642 & 100,0 & 2.052 & 100,0 & -1.590 & 56 \\
\hline
\end{tabular}

Fuente: Elaboración propia sobre Padrones municipales de habitantes.

No se ha registrado aumento alguno en el número de personas mayores de 60 años entre 1955 y 1981, pero sí se ha modificado sustancialmente la estructura por edades de una población que se ha reducido casi a la mitad; lo que significa que los mayores de 60 años han aumentado su importancia respecto a la población total, $y$, sobre todo, en relación con el grupo de menores de 20 años. Así, en 1955 representaban el 11 por 100 de todos los residentes en Bogarra y en 1981 la proporción se ha duplicado; en 1955 había 29 mayores de sesenta años por cada 100 menores de veinte y en 1981 este índice se ha elevado a 65, cuando la media provincial es de 46 y el índice medio de la capital no pasa de 32.

Consecuencia directa del éxodo de los años pasados ha sido la desaceleración del crecimiento natural.

Mi llamada de atención, en este caso, consiste especialmente en poner de manifiesto una dinámica demográfica que evoluciona de forma atípica respecto a las previsiones del modelo normalizado de transición demográfica. 
CUADRO III. TASAS DE CRECIMIENTO NATURAL (por mil)

\begin{tabular}{lccc}
\hline MUNICIPIOS & $1951-55$ & $1975-79$ & $1980-83$ \\
\hline AYNA $\ldots \ldots \ldots \ldots \ldots \ldots \ldots \ldots \ldots$ & 12,3 & $-0,9$ & $-2,9$ \\
BOGARRA $\ldots \ldots \ldots \ldots \ldots \ldots \ldots$ & 11,8 & 3,1 & 0,4 \\
PATERNA DEL MADERA $\ldots \ldots \ldots \ldots$ & 15,8 & 0,5 & 0,7 \\
RIOPAR $\ldots \ldots \ldots \ldots \ldots \ldots \ldots$ & 15,6 & 1,4 & $-2,4$ \\
\hline
\end{tabular}

Fuente: Elaboración propia sobre datos del INE.

En Albacete son 51 (entre 86) los municipios con tasas de crecimiento natural negativo en el cuatrienio 1980-1983 y en Castilla-La Mancha calculo que se dan en más del 70 por 100 de los municipios (J. SANCHEZ y A. CEBRIAN, 1988; J. SANCHEZ y E. GIL, 1984).

El proceso de agotamiento que esta situación genera es sumamente grave, como se aprecia en el cuadro siguiente, referido al municipio de Bogarra (Cuadro IV).

Este aspecto del deterioro demográfico es quizás el más grave en cuanto a consecuencias económicas, sociales y psicológicas en los municipios de montaña. Por lo tanto, es preciso detenerlo, poniendo en marcha todos los recursos disponibles para fijar a los jóvenes que todavia no se han marchado: porque pueden ser la última esperanza de revalorizar los espacios de montaña.

Efectivamente, hoy está transcurriendo una fase de acumulación de población joven entre 15 y 25 años y este es uno de los tres factores coyunturales positivos en la delicada situación demográfica. Los otros dos son los retornos y el aumento del número de pensionistas.

Gracias al fuerte frenazo de la emigración definitiva - por razones de crisis en las áreas y centros receptores- en los municipios serranos se puede contar hoy con una abundante población joven (en Bogarra, más de 350 individuos entre 15 y 25 años) que podría constituir el principal factor 
CUADRO IV. BOGARRA. VARIACION DE LOS MENORES DE 20 AÑOS ENTRE 1955 Y 1981

\begin{tabular}{|c|c|c|c|c|c|c|}
\hline \multirow{2}{*}{ EDAD } & \multicolumn{2}{|c|}{1955} & \multicolumn{2}{|c|}{1981} & \multicolumn{2}{|c|}{ VARIACION 1955-1981 } \\
\hline & Núm. & $\%$ & Núm. & $\%$ & Número & $\begin{array}{c}\text { Índice } \\
(1955=100)\end{array}$ \\
\hline Menores de 20 años & 1.399 & 38,4 & 639 & 31,1 & -760 & 45,7 \\
\hline Menores de 15 años & 1.023 & 28,1 & 433 & 21,1 & -590 & 42,3 \\
\hline Menores de 10 años & 684 & 18,8 & 249 & 12,1 & -435 & 36,4 \\
\hline Menores de 5 años .. & 342 & 9,4 & 113 & 5,5 & -229 & 33,0 \\
\hline Población Total ...... & 3.642 & 100,0 & 2.052 & 100,0 & -1.590 & 56,3 \\
\hline
\end{tabular}

Fuente: Elaboración propia sobre Padrones municipales de habitantes.

de dinamismo. Si se quiere invertir el actual proceso de deterioro demográfico y de ruina económica, es fundamental e imprescindible dar estabilidad y seguridad económica a estos jóvenes, porque si ellos se marchan, lo harian con los hijos que han empezado a nacer, y los pueblos quedarían así casi absolutamente desprovistos de recursos jóvenes.

La segunda consecuencia del reflujo emigratorio son los retornos. En 1981 llegué a contabilizar en Bogarra 14 familias con un total de 72 personas, de las cuales 44 eran hijos jóvenes y niños. La importancia que le concedo no se debe tanto al número - que es también importante-como al efecto psicológico que considero muy positivo, puesto que han vuelto no sólo agricultores-jornaleros, sino también algún comerciante, carpintero, electricista, etcétera. Estos retornos ayudan a cubrir servicios mal atendidos y a incrementar el nivel de satisfacción de ciertas necesidades de la colectividad; pero, además, está ayudando a crear un sentimiento de "revalorización", muy distinto a la actitud abandonista que se propagó en los años sesenta. $Y$ no se debe olvidar que el relativo optimismo y confianza en estas 
poblaciones de montaña es un capital de valor incalculable en una posible inversión del proceso demográfico y económico.

El tercer factor coyuntural positivo deriva de la propia estructura demográfica que está proporcionando un número cada vez mayor de pensionistas. La ampliación de cobertura de la Seguridad Social a los trabajadores agrarios permite contar ya con importantes ingresos por pensiones de jubilación. Estos ingresos fijos -que los recibe el 75 por 100 de los jubiladosconstituyen un complemento nada desdeñable para las precarias economias familiares. Los ingresos fijos aumentarán el nivel de consumo que, a su vez, deberá generar trabajo; y no sólo en la gama de servicios, sino también en las faenas agrícolas. En última instancia, la percepción de pensiones repercutirá en una mayor atención al campo y, si se ofrecen los estímulos suficientes, podrá constituir un factor real de desarrollo para la agricultura de montaña.

\section{RECURSOS FORESTALES Y GANADEROS SUBEXPLOTADOS}

La gran extensión de las masas forestales todavía conservadas es uno de los importantes recursos económicos con que cuentan estas poblaciones de la Sierra de Alcaraz. Sobre las plataformas y cumbres interfluviales se han mantenido unos excelentes pinares que se benefician de las condiciones ecológicas favorables de este sector, de una notable pluviosidad.

Aunque no faltan otras formaciones vegetales, son los pinares las únicas masas boscosas con alguna significación económica; y porque milagrosamente se han salvado de la acción desforestadora secular. La resinación incontrolada, la corta, de donde provenian los fondos municipales -en ocasiones con corporaciones desaprensivas-, la producción de carbón, la necesidad de combustible para las fábricas de San Juan de Alcaraz, la exigencia de tierras para el esparto, el aprovechamiento ganadero, las roturaciones agrícolas y los incendios, han sido los permanentes peligros para un bosque frágil que, desde luego, ha desaparecido de los montes más próximos a los centros de población. 
No obstante, la Sierra de Alcaraz, la Sierra del Agua, Yeguarizas, Calar del Cura y Calar del Mundo todavia cuentan con un volumen forestal importante, en su mayoría montes de Propios. Más o menos, y según el Catastro de Rústica, unas $21.000 \mathrm{Ha}$. de monte maderable y resinable en los cuatro municipios de Ayna, Bogarra, Paterna del Madera y Riópar; o sea, el 40 por 100 de toda la superficie municipal. Según el Censo Agrario de $1982,30.528 \mathrm{Ha}$. de especies arbóreas forestales. Si además le añadimos la superficie forestal no arbolada, obtenemos porcentajes muy altos de tierras forestales: 60 por 100 en Bogarra y 75 por 100 en los otros tres municipios. Hoy su explotación se ha reducido a la extracción de la madera y de la resina, pero, hasta hace poco, también se aprovechaban el esparto y las plantas aromáticas.

La ganadería es muy importante en algunas aldeas, principalmente el ovino; los prados, praderas permanentes y pastizales censados comprenden $4.167 \mathrm{Ha}$. La escasa calidad de los pastos hace que en el conjunto de los municipios no pase de ser un recurso complementario de la actividad agricola. Además de graves deficiencias en la estructura de las explotaciones, es muy irregular la venta de la producción ovina, hay gran inseguridad en los precios y una buena parte $(25-30 \%)$ es consumida en los propios municipios.

El aprovechamiento, pues, de los recursos tantos forestales como ganaderos está por debajo de sus posibilidades y cualquier proyecto global de desarrollo rural debe tener en cuenta esta situación de subexplotación.

\section{AGRICULTURA TRADICIONAL CON FUERTE MINIFUNDISMO $Y$ LA INEVITABLE EMIGRACION TEMPORAL}

Entre todas las actividades, la agricultura es la base económica principal de estas poblaciones. A pesar de que se trata de una agricultura pobre, de rendimientos muy aleatorios, mayoritariamente de autoconsumo y, sin lugar a dudas, muy insuficiente.

El mayor condicionante es la escasez de tierra cultivada. En total, se dispone de unas $8.800 \mathrm{Ha}$., que en Ayna representa el 28 por 100 de la superficie municipal, pero en Bogarra sólo alcanza el 16 por 100, en Riópar el 12 por 100 y en Paterna del Madera el 9,4 por 100. Esta escasez de tierras ha 
motivado una fuerte presión sobre las superficies forestales que han sido roturadas de forma implacable, logrando poner en cultivo grandes extensiones en los montes de Propios. En Bogarra, por ejemplo, se calcula que estas roturaciones, arrompios, pueden representar el doble de la superficie agrícola catastrada. En los otros municipios no han adquirido tanta importancia, pero en todos ellos, mientras no se resuelva el tema de la propiedad, pueden constituir un obstáculo en la necesaria reconversión de las explotaciones agrícolas.

La estructura de los cultivos se basa en tres producciones de autoconsumo (las de regadio en microparcelas, cereales y olivo) y una comercial, el almendro.

El regadío representa una extensión importante: más del 20 por 100 en el conjunto de los cuatro municipios. Bogarra es el que más tiene (unas 800 $\mathrm{Ha}$.), con una espléndida huerta en el río Madera; también en el arroyo de Haches. Hortalizas, frutales, alfalfa, maíz y, últimamente, choperas (en Paterna del M.), son los cultivos predominantes.

En el secano, los cereales ocupan bastante superficie, pero no es una producción con gran peso específico; es un complemento mínimo para la ganadería (cebada). Sin embargo, el olivo (1.500 Ha.), muy bien repartido, tiene un valor excepcional en la economía familiar; bien adaptado en Bogarra y Ayna, casi desaparece en Paterna del Madera y Riópar, cuyos valles son más altos y húmedos. El almendro, a pesar del riesgo permanente de las heladas (un año de cada cinco se pierde la cosecha o sufre grave daño), se ha extendido notablemente después de 1960 debido a su escasa exigencia de mano de obra y a su carácter comercial; es otro pilar importante de la economía familiar de estos valles, en los que ocupa grandes extensiones roturadas en los montes de Propios y en ocasiones en laderas de fuerte pendiente.

La misma presión demográfica en estos estrechos valles que ha obligado a roturar abusivamente sus laderas con pendientes excesivas ha provocado una fragmentación muy fuerte de la tierra, hasta extremos de absoluta gravedad.

Sin que estén ausentes algunas grandes propiedades agrícolas, lo que aquí domina es el minifundismo exacerbado. Para las $8.800 \mathrm{Ha}$. de suelo cultivado hay censados 5.385 propietarios: $¡ 1,6 \mathrm{Ha}$. por propietario! ¡más de la mitad de ellos posee menos de media hectárea! En cuanto a las explotaciones domina igualmente el microfundismo: el 70 por 100 tiene menos de $5 \mathrm{Ha}$., o sea, 992, de las 1.321 censadas en 1982. En la década de los 
sesenta hubo un importante reajuste en el grupo de las más pequeñas, pues de las 1.057 explotaciones menores de $2 \mathrm{Ha}$. en 1962, sólo quedaron 465 en 1972. Ello fue consecuencia del fuerte éxodo que sufrieron estos valles durante esos años.

En Bogarra la misma práctica secular del reparto hereditario ha provocado una extrema división de la tierra, en especial de las $500 \mathrm{Ha}$. de regadio permanente y de las $900 \mathrm{Ha}$. de olivares; pero también de las casi 2.000 $\mathrm{Ha}$. de almendro. Los 562 propietarios que aparecen en la relación del Amillaramiento de 1879 se han convertido cien años después en los 2.000, aproximadamente, que figuran en el Catastro de Rústica. Puede calcularse una media de tres a cuatro hectáreas por familia, integradas, casi de forma general, por cultivos de esa trilogía fundamental.

A pesar de todas sus deficiencias - en estructura de explotaciones, en productividad, en adecuación de cultivos, etc.- que deben ser subsanadas, la práctica de este tipo de agricultura, perfectamente calificable como de "tiempo parcial», ofrece, a mi parecer, dos importantes ventajas: la primera, que se basa en unos cultivos que exigen faenas muy localizadas en el tiempo y utilizan bastante mano de obra, pero permiten disponer de tiempo para las salidas en épocas intermedias; la segunda ventaja consiste en que se trata de unos productos mayoritariamente de consumo familiar - hortalizas, cereales, aceitunas para aceite y otro comercial, el almendro, que consigue ingresos en efectivo; $y$ tales producciones muy bien complementadas, junto con la posesión en propiedad de la tierra, a cuya pérdida se resisten hasta los mismos emigrantes, proporcionan una gran estabilidad y seguridad psicológica a los pequeños agricultores-jornaleros que son la mayor parte de los vecinos.

Este subsistema agrario genera consecuencias contradictorias: por un lado, la gran ventaja de fijar a la población agricola y, por otro, el notable inconveniente de no proporcionar suficientes recursos para la familia.

Por esta razón, la emigración temporal siempre ha sido una práctica necesaria y todavía hoy sigue siendo indispensable. Por otra parte, la localización geográfica de estas montañas permitió a los serranos sacar provecho de la proximidad a ciertas áreas de trabajo complementario y, con el tiempo, se ha creado tradición.

Todo ello explica que, pese al fuerte éxodo registrado en estas poblaciones, no se hallen entre los municipios con mayor emigración definitiva de Albacete. Sin embargo, son los que cuentan con mayor número de emi- 
grantes temporeros, en especial Bogarra, donde unas 700 personas vienen desplazándose anualmente, desde los años sesenta, a la vendimia francesa, lo que equivale a más de la tercera parte de la población municipal y a más del 70 por 100 del total en edad activa. Con unos 300 emigrantes temporeros por cada 1.000 habitantes, Bogarra es el primer municipio de Albacete, seguido de lejos por sus dos vecinos Paterna del Madera y Ayna, con 144.

Este es un elemento a tener muy en cuenta. Los municipios de la montaña albacetense disponen de una población activa ocupada sólo a tiempo parcial. Que presenta una especial disposición a permanecer en ellos por los vínculos sobre todo psicológicos y afectivos que le atan a la tierra de su propiedad, pero necesita realizar salidas de trabajo estacionales para completar sus ingresos familiares. Se trata de una población activa flotante, habituada a ello, de fácil desplazamiento y económicamente muy barata, puesto que se la contrata sin ningún problema por tiempo limitado. Este aspecto de la vida rural lleva consigo consecuencias negativas, como la escasez y el encarecimiento de la mano de obra en períodos de salida, el absentismo y fracaso escolar de los niños que han de desplazarse con los padres, etc. Sin embargo, y mientras no haya actividades alternativas en el interior o en la proximidad de estos municipios, una revalorización de la montaña debe tener presente a este colectivo "florante" y contemplar un doble aspecto: para los adultos, apoyados en sus pequeñas propiedades, basta asegurarles algunos de estos trabajos estacionales $u$ otros similares para no plantearse jamás la posibilidad de marcharse; para el grupo de jóvenes, que hoy tienen en estas salidas la única fuente de ingresos y que todavia no han accedido a la propiedad de la tierra, hay que imaginar alguna actividad aunque sea parcial, dentro del propio municipio. En caso de no conseguirlo, las salidas temporales no serán más que una preparación para la marcha definitiva. $Y$ con esta perspectiva, el joven se desentiende de los problemas de futuro del pueblo.

\section{LA NUEVA FUNCION DE LA MONTAÑA COMO ESPACIO DE OCIO. POSIBILIDADES Y PELIGROS}

En este contexto, hoy se debe contar con las posibilidades que la montaña ofrece en cuanto espacio de ocio. Pero conjurando desde el primer momento los graves peligros que de ello se derivan, objetivo que considero difícilmente alcanzable sin una acción integrada y eficaz. 
Estos valles tienen la suerte de que todavía son lugares poco conocidos por razones de localización. Riópar y Ayna están empezando a ser visitados y son los únicos núcleos donde se han construido recientemente algún tipo de infraestructura turística; pero en Bogarra y en Paterna la escasa demanda no ha logrado generar ningún proyecto digno de mención.

Efectivamente, las corrientes de visitantes afluyen con cierta regularidad a «Los Chorros» (nacimiento del río Mundo), en Riópar, y al cañón del mismo río Mundo, en Ayna. Más al interior, la distancia en kilómetros y en tiempo, recorrida por malas carreteras, actúa de obstáculo disuasorio para los no nativos. Sin embargo, son los propios habitantes, residentes o emigrados, los que han empezado a crear, por ejemplo en Bogarra, una presión ya peligrosa sobre estos espacios de gran valor ambiental, pero especialmente frágiles. En primer lugar, sobre el mismo pueblo, donde coincide la fiebre constructora con la absoluta escasez de suelo edificable y la ausencia de una normativa urbanística capaz de evitar los numerosos desatinos que se están produciendo. En segundo lugar, sobre uno de los parajes más atractivos del municipio - el Batán-pero fácilmente degradable.

Hoy, estos municipios están ya siendo contemplados, dentro de un plan global de la provincia de Albacete, como uno de los espacios de ocio potenciables (CARPIO, GONZÁLEZ y RIBERA, 1983). Podría ser utilizado especialmente desde la capital provincial y desde las poblaciones urbanas del Levante y Sureste.

La función de espacio de ocio constituye un recurso más de esta como de otras montañas. Pero personalmente estoy en contra de estimular una afluencia de visitantes, sin antes haber creado unas mínimas infraestructuras que potencien las posibilidades de "oferta" para ese "consumo» creciente de naturaleza y, a la vez, garanticen la defensa y correcta utilización de un bien tan apreciado como escaso. A partir de determinados umbrales de densidad, la presión demográfica desde el exterior puede ser nociva y aún desastrosa.

Por lo tanto, los importantes recursos ambientales, hasta hoy infrautilizados, deben ser tenidos en cuenta en la posible reactivación de estas áreas de montaña. Pero igualmente, antes de que sea demasiado tarde, el desarrollo turístico ha de contemplarse dentro de un planteamiento general de ordenación, valoración y aprovechamiento integral de la montaña. 


\section{PRIORIDAD DE LA RENTABILIDAD SOCIAL Y ECOLOGICA EN LAS POLITICAS DE DESARROLLO RURAL DE MONTAÑA}

Considero que no es posible encontrar soluciones definitivas, y desde luego y de ninguna manera únicas, para un problema tan complejo y múltiple como es la crisis de los espacios montañosos. Pero participo de la idea de que no deben seguir abandonados como hasta ahora lo han estado, y de que «el bienestar social más deseable en las áreas deprimidas pasa por la promoción de distintas actuaciones acumulativas con escasa inversión financiera, aprovechando los recursos naturales y potenciando la gestión de las Corporaciones Locales y colectivos sociales» (CARPIO, 1984, pág. 177).

Son absolutamente necesarios los análisis previos en profundidad y la valoración prudente de los recursos naturales, sobre la base del respeto a la naturaleza y a todo valor cultural y ambiental. El desarrollo económico en áreas deprimidas de montaña, más que en ningún otro lugar, debe apoyarse en la convicción de que se trata de bienes escasos, desde el suelo agrícola o el espacio edificable, hasta los recursos forestales y faunísticos, la población activa y joven, la belleza paisajística y la pureza de las aguas.

Por ello, toda actuación sobre un territorio montañoso debe partir de una actitud prudente y reflexiva. La supervivencia de las poblaciones montanas exige la explotación racional de todos los variados recursos, simultáneamente.

En el caso concreto de los municipios referidos, la revalorización supone actuar conjuntamente y de forma prioritaria sobre los factores y elementos clave, capaces de romper el círculo vicioso de la pobreza y de invertir el rumbo del proceso involucionista.

La rentabilidad social y ecológica de la montaña merece que se realice un gran esfuerzo para conseguir la estabilidad demográfica de esos municipios. Dejando de lado los principios del modelo desarrollista, existen resortes suficientes para conseguirlo. En mi opinión, y refiriéndome al espacio concreto que he analizado en esta comunicación, podría ser acertado partir de los siguientes principios y objetivos:

1) Proteger la existencia del minifundio sobre la estructura productiva de hortalizas-frutales, cereal, olivo y almendro. Habria, en todo caso, que arbitrar 
medidas para mejorar la rentabilidad y garantizar precios en productos enviados al mercado. Habría que plantear la necesidad de una concentración parcelaria - a la que son reacios tanto los propietarios presentes como los ausentes-, mejorar los accesos a las áreas cultivadas para facilitar la mecanización, ampliar los regadíos potenciando en ellos algún producto comercial, impedir la ruina del olivo, protegiéndolo casi como un bien cultural, resolver el conflicto pendiente de las roturaciones en bienes de Propios, etc.

2) Considerar como complemento económico imprescindible la emigración temporal; y, mientras no existan alternativas suficientes de trabajo, comprometerse a tutelar, facilitar y hasta garantizar las salidas tradicionales más regulares, incluso imaginando fórmulas nuevas en relación a trabajos que puedan aceptar contrataciones temporales.

3) Con el propósito de retener a la población joven —objetivo prioritario-, es necesario desarrollar y programar el empleo dentro del municipio, aunque sea intermitente, como puede ser el trabajo de la construcción y obras públicas, que debería proyectarse en épocas de no emigración. PANADERO MOYA (1984) ha apuntado la posible relación -creo que la relación es directa- entre la existencia de trabajos de obras públicas y la relativa estabilidad demográfica en algunos municipios del Suroeste albaceteño. Evidentemente, no es necesario que se trate de grandes proyectos. En este sentido, es también muy conveniente pensar en la creación de diversos talleres que podrian transformar artesanalmente las pequeñas producciones de la sierra.

4) Urge mejorar la rentabilidad de la explotación de maderas y resinas, con posible aumento de actividad y contrataciones fijas, aunque temporales; podría ser también conveniente replantear la viabilidad de aprovechamientos ya abandonados, como el de las plantas aromáticas, o poco desarrollados, como la apicultura.

5) En cuanto a la ganadería, bastaria con mejorar los canales de comercialización, y también la atención sanitaria, para conseguir una mayor participación de agricultores en esta actividad, hasta ahora demasiado minoritaria.

6) Importante también, desde el punto de vista de la revalorización de estos municipios, debe ser el acondicionamiento para espacio de ocio y la mejora de la calidad de vida, con especial atención a las actividades de servicios. No obstante, es requisito previo proteger eficazmente esos es- 
pacios ya sometidos a una fuerte inestabilidad natural, debido a su propia condición de montaña, y

7) A largo plazo, estos planteamientos deben llevar implícito el compromiso ineludible de una nueva educación que, ante otros valores, comporte mayor solidaridad, la primacia de valores ecológicos y estéticos, la renuncia a inversiones especulativas, la defensa a ultranza del patrimonio cultural y natural, asumir las limitaciones del espacio montañoso en cuanto a capacidad económica y presión demográfica, etc. $Y$ todo ello a cambio de mayor seguridad, más trabajo, nivel de vida más alto, mayores satisfacciones personales y mejor futuro para quienes vivan allí. Pero es imprescindible un cambio de mentalidad y adquirir nuevas pautas de comportamiento. $Y$ esto no será posible sin una intensa y permanente actividad cultural y educativa.

\section{NECESIDAD DE PROYECTOS GLOBALES Y ACCIONES INTEGRADAS}

Toda acción eficaz en favor de la montaña pasa necesariamente por un proyecto global articulando todos los elementos positivos y teniendo en cuenta todas las situaciones de bloqueo: debe evitarse cualquier proyecto parcial y desvinculado del plan general. Y hoy la mayor parte de las pocas obras públicas o privadas realizadas en este sector carecen de perspectiva espacial y temporal. La dinámica que puede generar la imprudencia y la falta de previsión tiene el riesgo de provocar una mayor desorganización, si cabe, del espacio montañoso.

Objetivo prioritario de este plan ha de ser la estabilidad demográfica, deteniendo el proceso de agotamiento y deterioro de los recursos humanos. Una fuerte inversión cultural hoy daría resultados muy positivos, aprovechando la coyuntura demográfica excepcional que presentan estos municipios, con un importante cambio generacional y con una breve fase de acumulación de población joven.

Es, pues, urgente e imprescindible lograr la fijación de estos jóvenes y comprometerlos en la construcción del futuro, ya que se requiere una mínima densidad de población y un mínimo de población activa para el conveniente mantenimiento de las actividades y servicios rurales. 
Conseguir esto exige una serie de acciones integradas, promovidas desde fuera y por los poderes públicos. Porque desde dentro, y en solitario, es impensable una reactivación, dado el carácter de sociedad bloqueada por sus propias estructuras y mentalidades. Sería una compensación a las dificultades en que se desenvuelve la vida en la montaña y supondría la cooperación en materia de explotación de recursos y mejora de la calidad de vida, garantizar la permanencia de la agricultura de montaña, frenar la tendencia especulativa del suelo, revalorizar los núcleos urbanos, mejorar sustancialmente los servicios, etc.

Estas acciones integradas deberán atacar el problema simultáneamente en sus tres principales frentes: el económico, considerando actividades tradicionales y posibilidades nuevas; el social, con la urgencia de revitalizar la demografía y dignificar la calidad de vida; y el cultural, respondiendo a la necesidad de forjar una nueva mentalidad de las poblaciones que viven o visitan la montaña, acorde con los nuevos planteamientos.

En estos proyectos globales deben comprometerse firmemente los poderes públicos, en sus niveles superiores: estatal, regional y provincial; pero, sobre todo, ha de contar con el protagonismo indiscutible de los propios municipios, a través de la iniciativa de las respectivas Corporaciones y de la participación de todos sus habitantes, residentes y emigrados, individual o colectivamente. La Ley 25/1982 de Agricultura de Montaña contempla la existencia de Programas de Ordenación y Promoción de Recursos Agrarios de Montaña (PROPROM); pero es posible que pasen todavía algunos años hasta que se regulen convenientemente y empiecen a ponerse en práctica.

\section{CONCLUSION}

El desarrollo integral de la montaña se ha de basar necesariamente sobre dos tipos de factores: los recursos internos, limitados pero realmente disponibles, y las acciones emprendidas desde el exterior, que han de traer incorporado el principio de protección a la montaña.

La revalorización de las áreas montañosas exige la sensata cooperación tierra alta-tierra baja y montaña-llano-ciudad, aceptando de antemano la vocación esencialmente ecológica de estos espacios. 
Siempre que se apliquen estos principios generales, el sector de la Sierra de Alcaraz ofrece evidentes perspectivas de desarrollo: han de combinarse actividades agrarias y extra-agrarias a través de proyectos globales y acciones integradas. 


\section{BIBLIOGRAFIA}

BalCells Rocamora, E. (1981): «El concepto ecológico de territorio montañoso: revisión general». Supervivencia de la montaña. Actas del Coloquio hispano-francés sobre áreas de montaña. Ministerio de Agricultura, págs. 51-67.

Cabero DiÉguez, V. (1980); «Estado actual de las regiones de montaña". La región y la geografía española. Asociación de Geógrafos Españoles, Valladolid, págs. 243-258.

Carpio Martín, J. (1984): "Los espacios de ocio en la provincia de Albacete. Una propuesta de actuación". Al-Basit, Revista de Estudios Albacetenses, núm. 14, págs. 167-177.

Carpio Martín, J., González, J. y Ribera, D. (1983): “Criterios para el planeamiento urbanístico de la provincia de Albacete". Al Basit, Revista de Estudios Albacetenses, núm. 12, págs. 197266.

HERIN, R. (1975): “Les populations du haut bassin du Segura: Une depopulation tardive et accelerée". Papeles del Departamento de Geografia-6. Universidad de Murcia, págs. 51-95.

Panadero Moya, M. (1988): «Movimientos de población en las sierras albacetenses durante la última década». III Seminario de Geografía, Albacete, 1984. Instituto de Estudios Albacetenses, págs. 118-131.

SÁNCHEZ SÁNCHEZ, J. (1979): "Los movimientos migratorios en la provincia de Albacete". Papeles del Departamento de Geografía-7. Universidad de Murcia; págs. 53-90. 
SÁnCHez SÁnCHeZ, J. (1984): "Bogarra en el siglo XIX: Agricultura tradicional en la Sierra de Alcaraz". I Congreso de Historia de Albacete, 1983. Instituto de Estudios Albacetenses, Albacete, t. IV, págs. 225-241.

-: (1986): «Problemas de desarrollo rural en la Sierra de Alcaraz y su difícil solución. El ejemplo de Bogarra». Al-Basit, Revista de Estudios Albacetenses, núm. 18, págs. 105-119.

Sánchez SÁnchez, J. y Cebrián, A. (1988): "Proceso emigratorio y regresión demográfica en la provincia de Albacete». III Seminario de Geografía de Albacete, Albacete, 1984. Instituto de Estudios Albacetenses, págs. 154-172. 


\section{MAPA DE SITUACION}

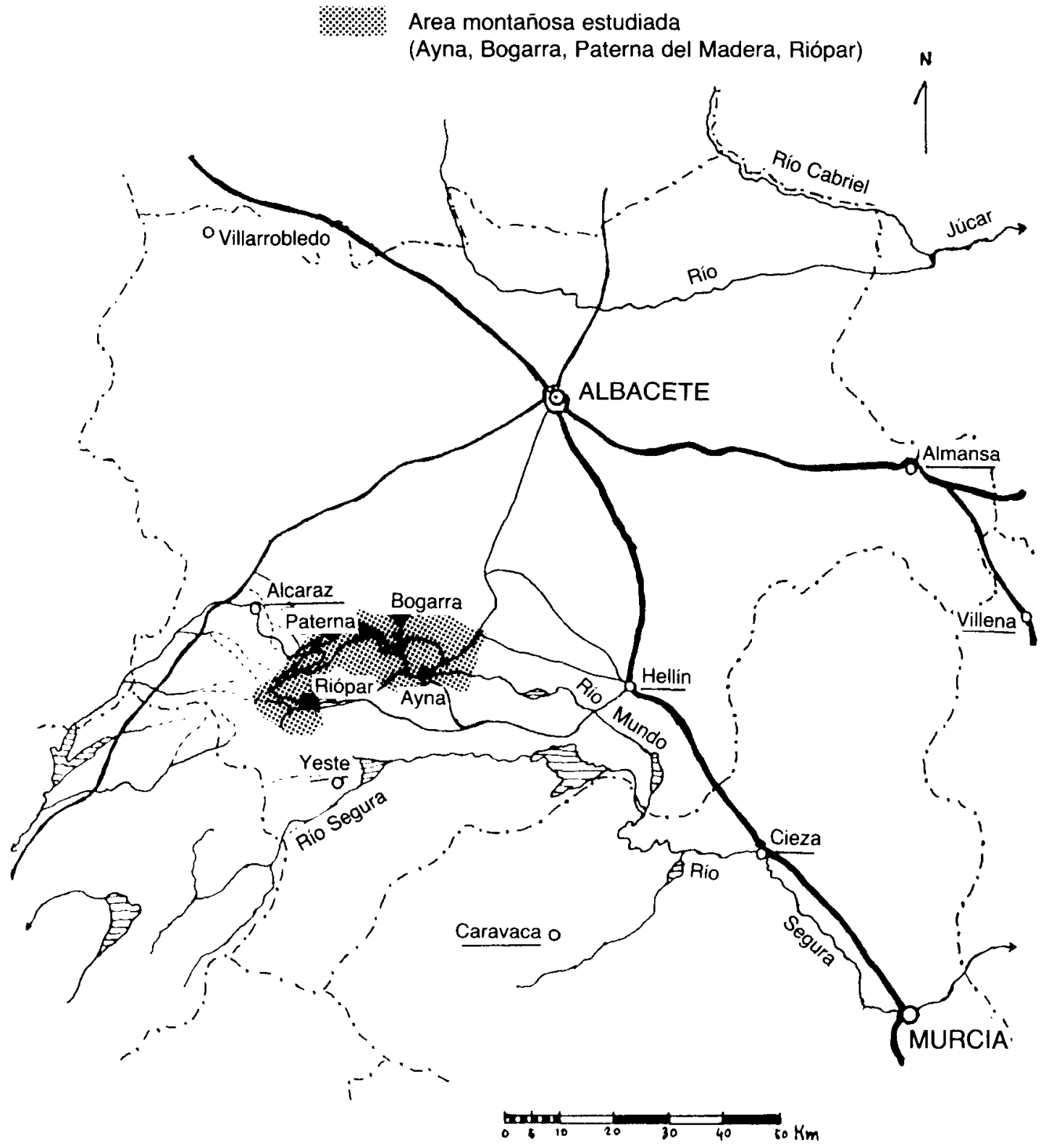

FIGURA 1 
BOGARRA 1981

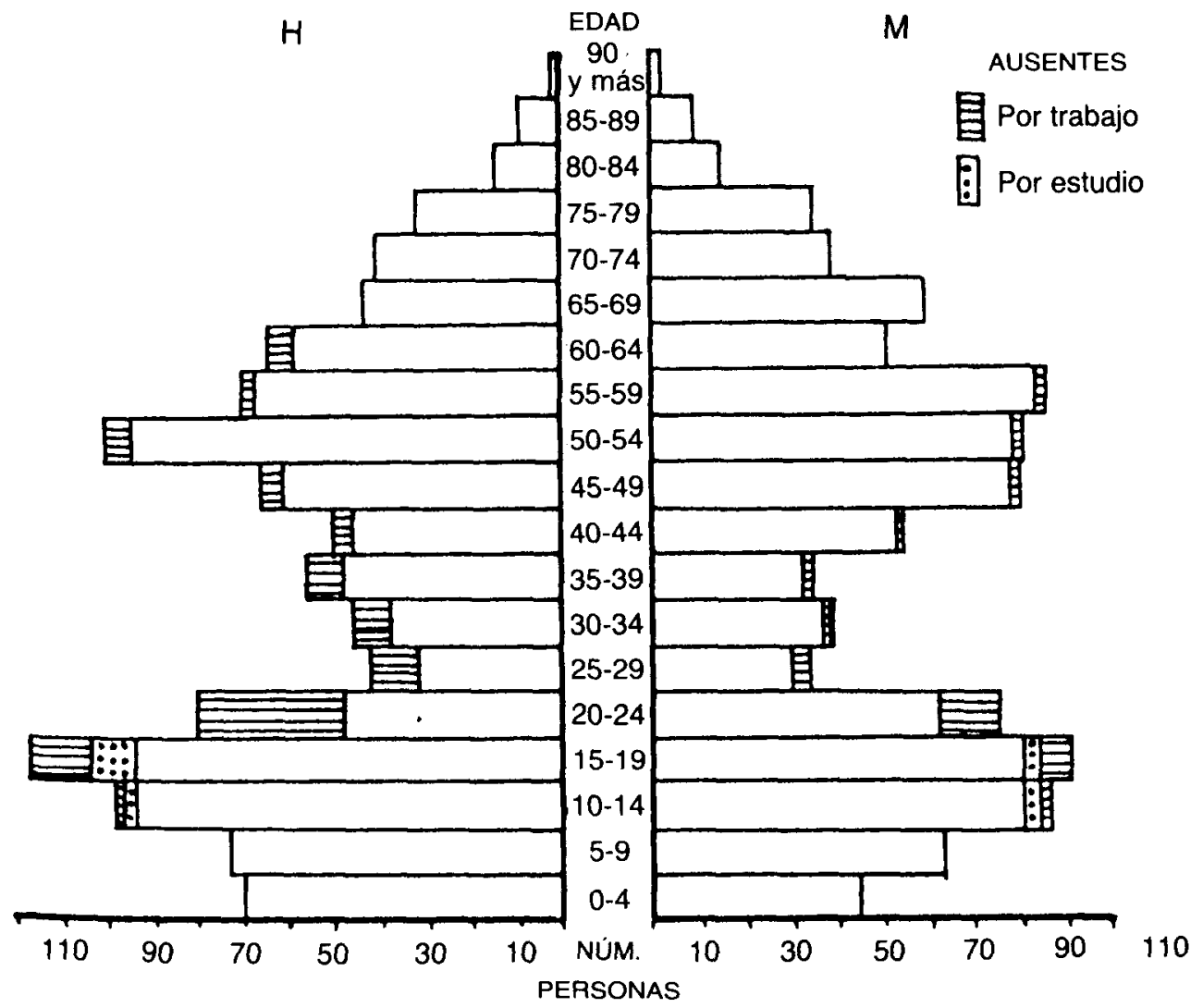

FIGURA 2 